\title{
Lietelannan levitys sokerijuurikkaalle kasvukaudella
}

\author{
Kimmo Rasa*, Marja Turakainen**, Susanna Muurinen** \\ *TEHO-hanke, Lounais-Suomen ympäristökeskus. kimmo.rasa@ymparisto.fi \\ **Sokerijuurikkaan Tutkimuskeskus.marja.turakainen@nordicsugar.com
}

\section{Tiivistelmä}

Lannan levitys sokerijuurikasmaille on ongelmallista aikaisesta kylvöstä ja myöhäisestä sadonkorjuusta johtuen, jolloin kasvukauden ulkopuolisina levitysajankohtina maa on usein märkää ja helposti tiivistyvää. Levittämällä lanta kasvukauden aikana, voidaan mahdollisesti vähentää maan tiivistymistä ja samalla vältetään ravinteiden talviaikainen huuhtoutuminen syksyllä levitetystä lannasta. Lisäksi tehostamalla lannan hyödyntämistä, voidaan vähentää väkilannoitteiden käyttöä ja niiden ostosta aiheutuvia kustannuksia.

Juurikkaan kasvukausi on pitkä ja sen ravinteiden otto on suurimmillaan heinäkuussa. Siten se pystyy hyödyntämään tehokkaasti kasvukaudella levitetyn lietelannan ravinteet. Kasvukaudella 2009 toteutetussa kokeilussa peltolohkon kahta koekaistaa lannoitettiin eri tavoin. Väkilannoitekaista sai Nja K-lannoitteina $120 \mathrm{~kg} \mathrm{~N} \mathrm{ha}^{-1}$ ja $30 \mathrm{~kg} \mathrm{k} \mathrm{ha}^{-1}$ sekä lietelantakaista $\mathrm{N}$-lannoitteena ja lietelantana $66 \mathrm{~kg}$ $\mathrm{N} \mathrm{ha}^{-1}, 12 \mathrm{~kg} \mathrm{P} \mathrm{ha}^{-1}$ ja $22 \mathrm{~kg} \mathrm{~K} \mathrm{ha}^{-1}$. Lietteen levitystä kokeiltiin ensiksi sijoittavalla levityslaitteistolla, mutta kasvuston vioittumisen vuoksi levitysmenetelmä vaihdettiin letkulevitystä vastaavaksi.

Keväällä lohkolta otettiin maanäytteet viljavuusanalyysiä varten. Juurikkaan taimettumista seurattiin taimilaskennan avulla. Kasvuston lehtivihreän määrää arvioitiin SPAD-mittarilla kolme kertaa kasvukauden aikana. Lietevaunun vaikutusta maan tiivistymiseen $(35 \mathrm{~cm})$ tarkasteltiin penetrometrillä. Juurisadon määrä, juurikkaan keskipaino sekä sadon sokeri-, aminotyppi-, kalium- ja natriumpitoisuudet määritettiin nostetusta sadosta.

Kenttähavaintojen perusteella todettiin, ettei käytetty sijoittava levityskalusto sovellu lannan levittämiseen juurikaskasvustoon. Sijoittava kalusto vioitti juurikaskasvustoa huomattavasti, kun kaluston vannasväli oli $17 \mathrm{~cm}$ ja juurikkaan riviväli $45 \mathrm{~cm}$. Letkulevityksessä lanta puolestaan imeytyi hyvin maahan, eikä kasvusto likaantunut merkittävästi. Kesäkuun loppupuoli osoittautui hyväksi ajankohdaksi toimenpiteelle, sillä kasvusto on vielä avointa ja voi toipua tallauksesta.

Maa oli tiiviimpää lietevaunun renkaan urassa kuin sen vieressä, mikä osittain johtunee poikkeuksellisen märistä levitysolosuhteista. Lietelantakaistan alhaisempi typen lannoitusmäärä näkyi juurikkaiden aminotyppipitoisuudessa, joka oli lietelantakaistalla alhaisempi kuin väkilannoitekaistalla. Kasvukauden aikana mitatut SPAD-tulokset tukevat tulosta. Väkilannoitekaistan sato kehittyi hyväksi ilman fosforilannoitustakin.

Levityskalustoa kehittämällä ja ajouria käyttämällä kasvukauden aikaisen lannanlevityksen aiheuttamaa kasvuston vioittumista voitaisiin mahdollisesti vähentää. Lietteen levityksen siirtäminen kasvukaudelle ei automaattisesti poista tiivistymisriskiä, vaan maan kosteustilaan tukee edelleen kiinnittää huomiota. Hyvä keino tiivistymisriskin pienentämiseksi on suosia mahdollisimman kevyttä levityskalustoa.

Asiasanat: sokerijuurikas, lannan levitys, sijoittava kalusto, letkulevitys, kasvukausi, sato 


\section{Johdanto}

Lietelannan levitys sokerijuurikkaalle kasvukaudella -kokeilussa yhdistyvät käytännön viljelytyön haasteet ja vesiensuojelun näkökulma. Lannan levitys sokerijuurikasmaille on ongelmallista aikaisesta kylvöstä ja myöhäisestä sadonkorjuusta johtuen, jolloin mahdollisina levitysajankohtina maa on märkää ja helposti tiivistyvää. Lannan levitysalasta puolestaan voi olla jopa pulaa tietyillä LounaisSuomen alueilla. Ympäristönäkökulmasta tiivistymisongelmien minimointi ja lannan levityksen siirtäminen kasvukaudelle ovat suotavia, sillä hyvärakenteisessa maassa ravinteiden hyödyntäminen on tehokasta ja ennen talvea levitettävästä lannasta ravinteiden huuhtoutumisriski on suuri. Lisäksi lisäämällä lannan hyödyntämistä voidaan vähentää väkilannoitteiden käyttöä ja edelleen siitä aiheutuvia kustannuksia.

Lietelannan typen lannoitustehokkuuteen vaikuttavat levitysajankohta, levitystapa ja kasvukauden sääolot (Maidl ja Fiscbeck 1989). Lannan ja lannoitteiden levittämistä kasvukaudella on hyödynnetty viljan viljelyssä jo pitkään. Sokerijuurikkaan viljelyssä on edellytykset hyödyntää samaa käytäntöä, juurikkaan kasvuaika on pitkä ja sen ravinteiden otto on suurimmillaan heinäkuussa (Draycott \& Christensen 2003). Sen vuoksi juurikas pystyy hyödyntämään tehokkaasti kasvukaudella levitetyn lietelannan ravinteet. Kokeilun tavoitteena oli testata käytännössä lietelannan levitystekniikkaa sekä kasvukaudella toteutetun levityksen vaikutusta sokerijuurikkaan sadonmäärään ja laatuun.

\section{Materiaali ja menetelmät}

Kokeilu toteutettiin Varsinais-Suomessa sadontuottokyvyltään hyvällä juurikaslohkolla kasvukaudella 2009. Lohko kynnettiin syksyllä 2008 ja keväällä 2009 juurikas kylvettiin yhdistelmäkoneella 2.5 . tasausäestyksen jälkeen (riviväli $45 \mathrm{~cm}$, siemenetäisyys $15 \mathrm{~cm}$ ). Kokeilussa käytettiin sertifioitua Festifal-siementä. Kasvinsuojelu tehtiin tilan normaaliohjelman mukaisesti.

Koejärjestely koostui kahdesta 300 m pitkästä kaistasta, jotka lannoitettiin joko pelkällä väkilannoitteella tai sian lietelantaa hyödyntäen. Kaistoihin sijoitettiin koeruudut (4 kpl/käsittely). Ruudut olivat $10 \mathrm{~m}$ pitkiä ja niissä oli 4 riviä. Lietelannan levitys tehtiin ennen rivivälien sulkeutumista, 22.6. Lanta-analyysiä varten lietelannasta otettiin näyte ennen levitystä. Lanta oli tarkoitus alun perin levittää riviväleihin sijoittavalla lannanlevityskalustolla, mutta levittimen vannasvälit eivät soveltuneet juurikkaan riviväleihin ja aiheuttivat huomattavaa vioitusta. Levitys tehtiin lopulta "pintalevityksenä" vantaat ilmassa, joka vastaa lähinnä letkulevitystä. Levitys tehtiin $16 \mathrm{~m}^{3}$ levitysvaunulla (Livakka Oy, Suomi). Työleveys oli 8 metriä ja vantaiden väli oli $17 \mathrm{~cm}$.

Väkilannoitekaista lannoitettiin kylvön yhteydessä ammoniumnitraatilla ja kaliumsulfaatilla (120 $\mathrm{kg}$ typpeä/ha ja $30 \mathrm{~kg}$ kaliumia/ha), lietelantakaistalle annettiin keväällä vain ammoniumnitraattia (40 $\mathrm{kg}$ typpeä/ha). Lietelannan levitysmääräksi mitoitettiin $20 \mathrm{~m}^{3} / \mathrm{ha}$, mutta toteutunut levitysmäärä jäi hieman alhaisemmaksi, noin $17 \mathrm{~m}^{3} / \mathrm{ha}$ (26 kg typpeä/ha, $13 \mathrm{~kg}$ fosfori/ha, $22 \mathrm{~kg}$ kalium/ha). Lietelantalohkon ravinnemäärät olivat siten yhteensä $66 \mathrm{~kg} \mathrm{~N} / \mathrm{ha}, 12 \mathrm{~kg} \mathrm{P} / \mathrm{ha} \mathrm{ja} 22 \mathrm{~kg} \mathrm{~K} / \mathrm{ha}$ ). Alkuperäisesti lannoitus oli suunniteltu samansuuruiseksi molemmille käsittelyille, mutta käytännön olosuhteista johtuen (mm. lannan alhainen typpipitoisuus) lannoituserot olivat huomattavat. Lietelannan ravinnepitoisuudet tuorepainoa kohtia olivat 2,39 kg tn ${ }^{-1}$ kokonaistyppeä, $1,54 \mathrm{~kg} \mathrm{tn}^{-1}$ liukoista typpeä $\left(\mathrm{NH}_{4}-\mathrm{N}\right)$, $0,76 \mathrm{~kg} \mathrm{tn}^{-1}$ fosforia ja $1,31 \mathrm{~kg} \mathrm{tn}^{-1}$ kaliumia.

Taimilaskenta ja kasvuston lehtivihreämittaukset tehtiin SPAD-mittarilla (Minolta-502) typen riittävyyden seuraamiseksi koeruutujen kahdesta keskimmäisestä rivistä. Kasvuston peittävyys arvioitiin elokuun lopussa koeruuduista. Kahden keskimmäisen rivin juurikkaat (halkaisija $>4 \mathrm{~cm}$ ) nostettiin syksyllä (22.9) käsin ja toimitettiin analysoitavaksi. Lantavaunun aiheuttamaa maan tiivistymistä mitattiin penetrometrillä sekä renkaan jäljestä että sen vierestä.

Satotulosten tilastollinen analysointi suoritettiin SAS-ohjelmalla. Parittaiset vertailut tehtiin Tukey'n testillä merkitsevyystasoilla $\mathrm{P}<0,01$ ja $\mathrm{P}<0,05$.

\section{Koetulokset}

Juurikkaan taimettumisnopeudessa ja taimettumisen tasaisuudessa ei ollut eroja käsittelyjen välillä. Neljän viikon kuluttua kylvöstä lasketut taimitiheydet olivat lietelantakaistalla hieman alhaisemmat 5.3 tainta/rivimetri kuin väkilannoitekaistalla 5.7 tainta/rivimetri. Kasvuston peittävyys oli elokuun lopulla väkilannoitekaistalla $100 \%$ ja lietelantakaistalla $85 \%$. Tulos osoittaa, että lietelantalohkon kasvusto on alhaisemmasta typen määrästä johtuen jäänyt pienemmäksi. Alhaisemman lehtialaindek- 
sin on osoitettu olevan yhteydessä juurisadon määrään (Tsialtas \& Maslaris 2008). Lehdistä mitatussa lehtivihreän määrässä (SPAD-arvot) ei ollut merkitseviä eroja väkilannoite- ja lietelantakaistojen välillä kasvukauden aikana (Kuva 1). Lietelantalohkon alhaisempi typpilannoitus näkyi tuloksissa kuitenkin hieman alhaisempina SPAD-arvoina. Sekä väkilannoite- että lietelantakaistoilla kasvustojen lehtivihreän määrä oli korkein 30.6. mittausajankohtana. Suomessa tehdyissä tutkimuksissa sokerijuurikkaan yleisen kasvukunnon ja sadontuoton kannalta optimaaliset SPAD-arvot ovat 37-41 (7-8 lehteä auki) ja 42-46 (9 tai useampi lehti auki) (Peltonen 1997).

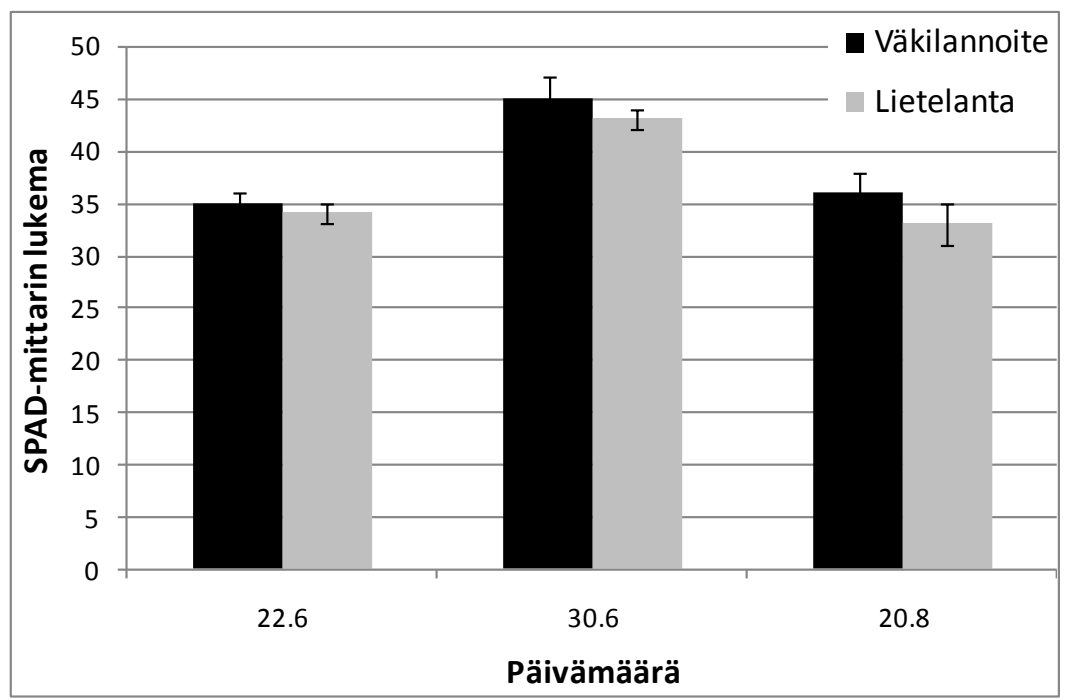

Kuva 1. SPAD- mittauksen lukemat ennen lietteen levitystä 22.6, lietteen levityksen jälkeen 30.6 sekä syksyllä 30.8. Virhepalkit kuvaavat keskihajontaa.

Väkilannoitekaistalla juurikkaiden kappalemäärä koenostetulla ruudulla oli suurempi ja juurisato oli lähes $17 \%$ korkeampi kuin lietelantakaistalla (Taulukko 1). Lähes yhtä suuri juurikkaiden keskipaino lietelantakaistalla selittyy alhaisemmalla juurikkaiden lukumäärällä ruutua kohden. Lietelantakaistan alhaisempi typen lannoitusmäärä näkyi juurikkaiden aminotyppipitoisuudessa, joka oli lietelantakaistalla alhaisempi kuin väkilannoitekaistalla. Koekaistojen juurikkaiden laatuominaisuudet, sokeriprosentti, kalium- ja natriumpitoisuus eivät eronneet eri käsittelyjen välillä. Laadulle asetettujen tavoitteiden mukaan juurikkaiden sokeriprosentti oli molemmissa käsittelyissä hyvä ja kalium- ja natriumpitoisuudet erinomaiset.

Taulukko 1. Juurisato ja laatutulokset sekä tilastolliset merkitsevyydet $* *(\mathrm{P}<0,01, *(\mathrm{P}<0.05)$ eri käsittelyjen välillä.

\begin{tabular}{lll}
\hline & Väkilannoite & Lietelanta \\
\hline Juurisato tn/ha & $48.0^{*}$ & 39.6 \\
Sokeri-\% & 16.3 & 16.7 \\
Aminotyppi mg/100 g & $11.9^{* *}$ & 8.0 \\
Kalium me/100 g & 4.0 & 4.1 \\
Natrium me/100 g & 0.44 & 0.37 \\
Kpl/ruutu & 105 & 94 \\
Keskipaino kg/ruutu & 0.41 & 0.39 \\
\hline
\end{tabular}

me=milliekvivalentti

Lietelantalohkolla lietevaunun vaikutusta maan lujuuteen mitattiin penetrometrin avulla (Kuva 2). Penetrometri mittaa tarvittavaa voimaa, kun metallista kartiota painetaan maahan. Tulokset osoittavat, että maa on tiiviimpää ajouralla kuin muulla pellon osalla koko mittaussyvyydellä $(35 \mathrm{~cm})$. Lietevaunun leveät renkaat tallasivat kaksi juurikasriviä, mutta kasvusto toipui melko hyvin kasvukauden loppuun mennessä. 


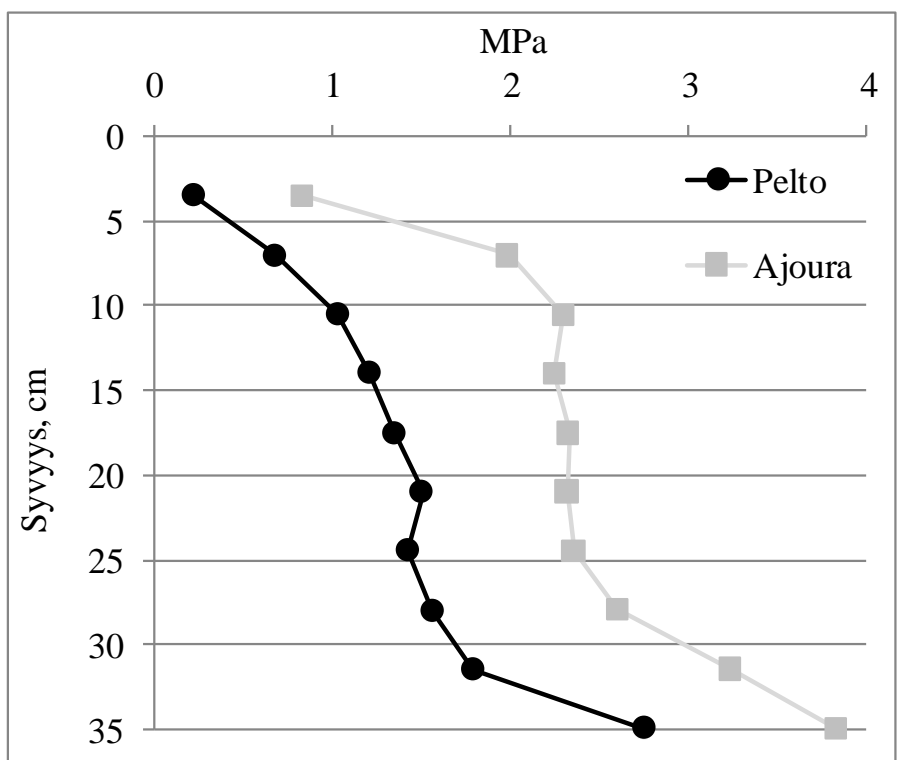

Kuva 2. Penetrometrin vastuslukema (MPa) muokkauskerroksen eri syvyyksissä lietevaunun ajouralla ja tallaamattomalla pellolla 20. 8 .

\section{Tulosten yhteenveto}

Kokeilun tavoitteena oli testata sijoittavan lannanlevityskaluston soveltuvuutta kasvukauden aikaiseen lannanlevityksen juurikkaan viljelyssä. Lannan sijoittamisen etuna pintalevitykseen verrattuna on vähäisempi typen haihtuminen ja siten parempi typen lannoitusvaikutus (Mattila 2006). Lisäksi sijoittamalla lietelanta ravinteet saadaan lähemmäksi juuristoa ja samalla vähenee riski pintavalunnalle. Sijoittava kalusto kuitenkin vioitti juurikaskasvustoa huomattavasti, kun kaluston vannasväli oli $17 \mathrm{~cm}$ ja juurikkaan riviväli $45 \mathrm{~cm}$. Levityskalustoa kehittämällä ja ajouria käyttämällä vioitusta voitaisiin mahdollisesti vähentää.

Sokerijuurikkaan kasvuston kehitysvaiheen kannalta kesäkuun loppupuoli on sopiva levitysajankohta. Juurikkaan naatti ei vielä silloin peitä rivivälejä ja lietteen levittäminen riviväleihin onnistui naatiston pahemmin likaantumatta. Lehdet eivät myöskään vioittuneet levityksessä. Levitetty lietelanta imeytyi nopeasti maahan ja maan pinnalle jäi vain hieman orgaanista ainesta. Lietelannan letkulevittäminen juurikkaan kasvustoon on todettu toimivaksi ratkaisuksi myös aiemmissa kokeissa. Esimerkiksi Sokerijuurikkaan Tutkimuskeskuksen kokeissa saavutettiin hyviä satotuloksia, kun osa väkilannoitteesta korvattiin naudan lietelannalla (Kenttäkokeet 1991).

Raskaalla kalustolla tehtävä lannanlevitys tiivistää maan rakennetta, mikä havaittiin penetrometrillä tehdyissä mittauksissa. Kokeilussa lietelanta jouduttiin levittämään liian märissä olosuhteissa, mikä on lisännyt maan tiivistymistä. Myös kasvukaudella tehtävän lannanlevityksen ajoittuminen maan kosteuden kannalta soveltuvaan ajankohtaan on ensiarvoisen tärkeää. Maan tiivistymisriskiä voi vähentää suosimalla mahdollisimman kevyttä levityskalustoa.

Toteutunut lannoitus poikkesi huomattavasti koekaistojen välillä, mikä hankaloittaa kasvustoon levitetyn lannan lannoitusvaikutuksen tarkastelua. Tulosten perusteella voidaan kuitenkin todeta sadon määrän ja laadun kehittyvän hyväksi myös ilman fosforilannoitusta maan kasvukunnon ollessa riittävän hyvä. Lietelannan oletettua alhaisempi typpipitoisuus heikensi juurikkaan aminotyppipitoisuutta merkittävästi. Lannan typpilannoitusvaikutus on siten hyödynnettävä mahdollisimman tehokkaasti ja siksi juurikaskasvustoon soveltuvan sijoittavan laitteiston ja työtekniikan kehittämistä tulee harkita.

\section{Kirjallisuus}

Draycott, A. P. \& Christenson, D. R. 2003. Nutrients for Sugar Beet Production: Soil-Plant Relationships. Cronwell Press, Trowbridge UK. 242 s.

Kenttäkokeet 1991. Sokerijuurikkaan Tutkimuskeskus s. 57-58.

Maidl, F.X. \& Fischbeck, G. 1989. Effect of long-term application of farmyard manure on growth and quality of sugar beet. Journal of Agronomy and Crop Science 162: 248-255. 
Mattila, P. 2006. Ammonia emissions from pig and cattle slurry in the field and utilization of slurry nitrogen in crop production. Agrifood Research Reports 87: $136 \mathrm{~s}$.

Peltonen, J. 1997. Lisätypen tarve selviää lehtivihreämittarilla. Leipä leveämmäksi 3: $16 \mathrm{~s}$.

Sokerijuurikkaan viljelyopas 1999. Juurikassarka 2:102 s.

Tsialtas, J.T. \& Maslaris, N. 2008. Sugar beet response to $\mathrm{N}$ fertilization as assessed by late season chlorophyll and leaf area index measurements in a semi-arid environment. International Journal of Plant Production 2: 57-70. 